\title{
Determinants of College and University Choice for High-School Students in Qatar
}

\author{
Semsia Al-Ali Mustafa ${ }^{1}$, Abdel Latif Sellami ${ }^{1,}$, Engi Assaad Ahmed Elmaghraby ${ }^{1} \&$ Haneen Basheer Al-Qassass ${ }^{1}$ \\ ${ }^{1}$ Social and Economic Survey Research Institute, Qatar University, Doha, Qatar \\ Correspondence: Semsia Al-Ali Mustafa, Social and Economic Survey Research Institute, Qatar University, P.O Box \\ 2713, Doha, Qatar. Tel: 974-4403-3038. E-mail: semsia@qu.edu.qa
}

Received: April 4, 2018

Accepted: April 17, 2018

Online Published: April 24, 2018

doi:10.5430/ijhe.v7n3p1

URL: https://doi.org/10.5430/ijhe.v7n3p1

\begin{abstract}
This paper investigates various predictors of high school students' college and university choice decisions in Qatar. Based on a 2015 survey of 1,427 participants, this study utilized exploratory factor analysis to identify variables that affect student choice of higher educational institutions (HEI). Three factors were extracted from the analysis, revealing the following aspects of the academic experience as important when choosing a HEI: i) quality of education; ii) cultural values; and iii) the cost of education. Ordinal logistic regression was employed to test whether several independent variables (student's gender, nationality, parental education, and parental occupation) act as significant predictors of the three extracted dimensions (dependent variables). The analysis revealed, to varying degrees, that demographic characteristics significantly predict a student's HEI choice. Discussion on postulated reasons behind the recorded relationships will follow, along with implications and recommendations for further study and research. The study's findings will assist HEIs in Qatar and the broader region, to position themselves more effectively, and develop targeted strategies that attract and maintain a diverse student population.
\end{abstract}

Keywords: post-secondary educational plans, Qatar, factor analysis, regression

\section{Introduction}

Marketing has become the hallmark of modern institutions of higher education across the globe. With colleges and universities increasingly incorporated within the global education market, the educational landscape has become highly competitive. As such, colleges and universities are facing increased competition as they attempt to attract an ever-growing and diverse student base. Kinzie et al. (2004) noted that in order to stay financially viable and competitive, student-enrollment serves as "the lifeblood of colleges and universities" (p. 4). Mounting evidence shows that higher education marketing plays a significant role in recruiting college- and university-going students (Ivy, 2001, 2008; Lang, 2009; Noel-Levitz, 2012). Subjecting educational institutions to market forces has been a popular topic of debate (Bartlett et al., 2002; Bok, 2003; Newman et al., 2004), as some educators and decision-makers oppose the marketization of education, and dispute the idea of treating students as consumers or customers altogether (Holbrook, 2005; Sharrock, 2000).

In today's world of globalization and rapidly evolving technological advancements, having completed high school is no longer perceived as sufficient to maintain a comfortable standard of living (Cohen, 2016; Git, 2014). With more jobs demanding post-secondary education and training, attending further education is now considered a requirement to gainful employment. Belief in the traditional formula: "college $=$ white-collar job $=$ success", often motivates parents to prepare their children to engage in additional higher education. Since skilled job opportunities generally require post-secondary credentials, a college or university degree is "the ticket to a white-collar job and a middle-class lifestyle" (Kinzie et al., 2004, p. 15). It is therefore important to understand the determinants that underpin school-leavers' decisions to enroll in a HEI.

Research into the variables affecting student college and university choices is well established, particularly in the United States (Davignon, 2016; Hoyt \& Brown, 2003; Johnston, 2010; Kinzie et al., 2004; Moogan \& Baron, 2003; Perna, 2006). Additionally, similar work has been carried out in the UK (Briggs, 2006; Dunnett et al., 2012; Moogan \& Baron, C2003), Australia (Mazzarol, Choo \& Nair, 2001), and Canada (Drewes \& Michael, 2006; Lang, 2009). However, very little is still known about student educational choices in the Arab world. While limited in scope, this 
study paints a picture of important factors that determine student college or university choice in the context of an Arab country, Qatar, and offers an alternative perspective that may bridge this gap in the literature.

\subsection{Education in Qatar}

The State of Qatar exhibits an example of a market-driven system of higher education involving a number of rival institutions that actively recruit students. Home to many different nationalities, Qatar is a small Arabian Gulf state with a total population of 2,641.669 in 2017 (Ministry of Development Planning and Statistics, 2018). Estimates indicate that Qatari nationals make up less than $15 \%$ of the total population in the country. Abundant carbohydrate resources such as oil and natural gas have provided the nation with incredible wealth and its citizens with economic security for the past few decades, during which time the country has developed a reputation for massive investments in education, research, the arts, and science (Crist \& Powell, 2017).

The Education for a New Era (EFNE) reform - an initiative designed to overhaul the K-12 education in Qatar - was launched in 2002 (Brewer et al., 2007). Prompting educational institutions to embrace a market-oriented approach to their business activities, the EFNE led to a school system that consists of four types: i) independent schools; ii) international schools; iii) community schools; and iv) private Arabic schools. Qatari students often attend independent schools that are government-funded and gender-segregated, with separate schools for boys and girls, which respects the nation's conservative Muslim values.

The current education market in Qatar has fueled aggressive competition among colleges and universities, who offer various services and facilities to attract prospective students. Qatar University was inaugurated shortly after the independence of the country in 1973. Offering a range of nine Colleges including Arts and Sciences, Business and Economics, Education, Engineering, Health Sciences, Law, Medicine, Pharmacy, and Sharia and Islamic Studies), it is the oldest, largest, and only public university in the country.

Located in the so-called 'Education City', Qatar hosts satellite campuses for other universities, such as Virginia Commonwealth University, Carnegie Mellon University, Georgetown University, Northwestern University, Texas A\&M University, Weill Cornell Medical College, University College London, and HEC Paris (which offers executive education programs for mid-career and senior executives). These universities provide the same quality of education, programs and facilities that their main home campuses offer, with similarly high tuition fees.

Founded in 2010, Hamad Bin Khalifa University (HBKU) is a recent addition to the Education City, and a member of the Qatar Foundation for Education, Science, and Community Development. HBKU offers programs in Islamic studies, Humanities and Social Sciences, Science and Engineering, and Law and Public Policy. Other HEIs in Qatar include the Community College of Qatar that offers programs in Business, Computer Science, Humanities and Social Sciences; the College of the North Atlantic that offers programs by the School of Business Studies, the School of Engineering Technology and Industrial Trades, the School of Health Sciences, and the School of Information Technology; Stenden University that hosts-degree programs in Hospitality, Tourism and Management; and the University of Calgary that offers a Nursing program.

\section{Review of Literature}

Scholarship on the factors that determine student choice of a future institution of higher education has undergone significant changes over the past few decades, due to important educational and societal changes, including demographic and market characteristics, as well as institutional practices (Agrey \& Lampadan, 2014; Kinzie et al., 2004; Wiese, Van Heerden \& Jordaan, 2010). Many researchers contend that the decision to enroll in further education is a complex process that involves different perspectives and a myriad of factors (Brennan, 2001; Wiese, 1994).

Two distinctly dominant models of choice are identified in the literature, as an attempt to account for the reasons why students choose particular post-secondary institutions: one is based on an economic model, and the other is based on a sociological model (Chatfield, Lee \& Chatfield, 2012; Fernandez, 2010; Maringe, 2006; Somers, Haines $\&$ Keene, 2006). The economic model stipulates that students would choose a college or university when their choice decisions are associated with perceived costs and benefits (Cabrera \& La Nasa, 2000; Paulsen \& John, 2002). The sociological model maintains that students' gender, academic ability, socioeconomic status, the school context, and the opinions of significant others are the prime factors that influence their choice of HEI.

In their review of HEI choice models, Krezel and Krezel (2017) noted a set of social factors that influence a student's HEI choice, which fell into three broad types of influences: 1 . Student-related characteristics; 2 . Institutional factors; and 3. Greater social environment, i.e. the family and peers. Similarly, other research reports that HEI choice decisions are associated with Student characteristics (Goldrick-Rab, 2009; Hoxby \& Turner, 2013; Perna \& Steele, 
2011), Institutional variables (Belasco, 2013; Cabrera \& La Nasa, 2001; Kim \& Schneider, 2005; Plank \& Jordan, 2001), and Cultural influences (Hemsley-Brown, 1999; Lovenheim \& Reynolds, 2012; Nora, 2004). Despite the literature on the choice of HEI, it is not clear what the effects of these influences are.

Student characteristics such as race, gender, and socio-economic variables, noting parents' education levels, occupations, incomes (Rouse, 1995; Long, 2004) and academic abilities (Hossler, Braxton \& Coopersmith, 1989), are also recognized as influential on students' college/university choices. Other research referring to environmental factors in addition to parental income, considers family size, peer influence, residential area, and the distance from home to school as determinants of college enrollment decisions (Long, 2004; Townsend, 2007).

Institutional influences affecting student college/university choice include the institution's image and academic reputation, especially regarding the quality of courses and teaching (Baksh \& Hoyt, 2001), as well as the quality of the institution's academic and recreational facilities (Absher \& Crawford, 1996; Price et al., 2003). Research by Lagrosen, Seyyed-Hashemi and Leitner (2004) showed that the courses on offer, internal evaluations, computer facilities, and library resources are important factors that affect the post-secondary choice decisions that students make concerning enrollment in HEI. Other institutional factors included the availability of financial aid, employment opportunities, advertising (Kim, 2004; Van der Klaauw, 2002), the cost of tuition (Joseph \& Joseph, 2000), convenience and accessible location (Absher \& Crawford, 1996), and availability of programs sought (Yusof et al., 2008).

Research by Chung, Fam \& Holdsworth, (2009) reported how social and cultural factors are important predictors that shape the enrollment decisions for college-going students. Other research refers to the impact of significant others, i.e., parents, teachers, and friends who serve as role models, and influence the hopes and aspirations of college goers (Hossler, Braxton \& Coopersmith, 1989). In summary, the range of factors that students take into account when choosing a HEI differ in relevance, and vary according to students' social and cultural backgrounds.

\section{Significance}

Higher education is central to Qatar's effort to build national capacity, and transition into a knowledge-based society (Crist \& Powell, 2017). Beyond the key role they play in preparing human capital, HEIs are essential for economic and social progress and prosperity. Within the context of growing concern about the shortage of citizens equipped with the critical skills and competencies needed for the knowledge economy in Qatar, higher education plays a critical role. A distinctly heterogeneous and overwhelmingly foreign-born population in the education system places pressure on the need for more colleges and universities.

This research was motivated by the limited options available to students and their families in the country, particularly those who are not citizens. Whilst Qatari nationals have better access to the nation's only public university, Qatar University, and enjoy preferential enrollment and free tuition, accessing higher education continues to pose a real financial challenge to many, particularly foreign nationals residing in the country, who often resort to bank loans to cover the educational expenses of their children. Consequently, most non-citizen students seeking high quality higher education are left with two options: 1. To obtain a degree overseas, or 2. Obtain their degree at one of the private universities based in Qatar's Education City, and meet the exorbitant tuition fees.

\section{Research Questions}

The study-sought to (i) identify factors that significantly influence high school students' choice of a prospective college or university in Qatar, and (ii) examine the intersection of background characteristics, institutional traits, and socio-cultural variables, and their impact upon students' HEI choice. Concurrently, the study aimed to decipher the disparities reflected in student, institutional, and social and cultural influences.

The study was guided by two main research questions:

1) What factors drive students' choices of post-secondary institutions upon graduation in Qatar?

2) What background characteristics significantly predict the importance of these factors?

The study hypothesized that student background characteristics i.e. gender, nationality, and parental levels of education and occupation, significantly predicted their choice decisions regarding post-secondary education institutions. 


\section{Methodology}

\subsection{Participants}

The data collected for the study originate from the Qatar University Image Study (QUIS), a nationally representative survey conducted by the Social and Economic Survey Research Institute (SESRI) in November 2015. The QUIS consisted of two surveys administered to high school students and their parents. Due to resource constraints, the present study analyzed only the data on student participants.

The study included students attending $11^{\text {th }}$ and $12^{\text {th }}$ grades $(\mathrm{N}=1,427)$. Of these, $38 \%(\mathrm{~N}=461)$ were Qatari and $62 \%$ $(\mathrm{N}=966)$ non-Qatari. Amongst Qatari students who participated in the study, 54\% were in grade 11 and the remaining $46 \%$ were in grade 12 . With regard to non-Qatari students, $50 \%$ were from each grade. With respect to gender, female students constitute 53\% of all respondents. Overall, $84 \%$ of Qatari students were enrolled in independent schools while $46 \%$ of non-Qatari students were in independent schools, followed by Asian expatriate schools (22\%), and international schools (14\%). Only 5\% of Qatari students attended gender-mixed schools, whereas $41 \%$ of non-Qatari students attended gender-mixed school.

\subsection{Sampling Procedure}

Using information obtained from the Supreme Council of Education (replaced by the Ministry of Education and Higher Education in 2016 as part of a government reorganization), the sampling frame of this survey was developed by SESRI based on the list of all public and private schools operating in Qatar that offer grade 11 and grade 12 education. The sampling frame for the QUIS 2015 was developed by SESRI using school system information provided by the Ministry of Education.

To ensure the proportion of students in each stratum was similar between the frame and the sample, a proportionate sample allocation was utilized. The sample size of this survey was 35 schools with three schools refusing to participate, resulting in 32 surveyed schools. This sample design was taken into account when analyzing the data, to ensure unbiasedness and efficiency of the statistical estimates. Specifically, a weighting variable was created to account for different selection probabilities of students and non-responses. With the above number of completions, the sampling error was calculated to be $+/-3.9$ percentage points.

\subsection{Instrumentation}

A draft questionnaire was developed in English and then translated into Arabic, and researchers fluent in both Arabic and English reviewed the translation for accuracy. Respondents were asked to fill in either the Arabic or English version of the questionnaire. The data needed for the study was collected using paper-and-pencil questionnaires distributed in class. Upon receiving approval from the Internal Review Board at Qatar University, official letters requesting permission to conduct the study were submitted to the relevant schools. Students and their parents/guardians were informed in advance about the purpose of the study, that participation in the survey was voluntary and that all answers would be treated in strict confidentiality. The questionnaire was pre-tested with interviews of 38 students from three randomly selected schools. Based on data collected, field observations and suggestions made by the pretest field team, necessary adjustment were made in the wording and translation of the questionnaire.

\subsection{Measures}

The dependent variable was captured by responses to the statement "In general, how important is each of the following factors in your choice of where to apply to college/university?" on a three-point Likert scale (1= Very important, $2=$ Somewhat important, and $3=$ Not important). The set of items to evaluate included: (a) Lower education cost (e.g., low tuition, fees); (b) Financial aid/scholarship; (c) Quality of academic programs; (d) Quality of professors/ teachers; (e) Quality of student life; (f) Availability of programs/majors I am interested in; (g) Availability of degree programs that offer good job opportunities; (h) Prestige of the university/ college; (i) Recognition of the degrees in other countries (accreditation); (j) Instruction in Arabic; (k) Instruction in English; (l) Separate campuses for male and female students; (m); Easy admissions criteria; (n) Campus environment is conducive to my culture/values; (o) Family member(s) attending/attended the college/ university; (p) Friends plan to attend the college/university; (q) Size of the college/university campus; and (r) Total number of students.

Based on the factor analysis, three dimensions were extracted: 1. Quality of education; 2. Cultural values, and 3. Cost of education, which were used as the dependent variables in the analysis. Details of the factor analysis will be further discussed in the Results section. 
Independent Variables: Five independent variables were employed in this study: gender, nationality, parents' highest level of education, father's occupation and mother's occupation.

Gender. The gender variable was dichotomized into $0=$ Female and $1=$ Male.

Nationality. Given the specific demographic composition of the population in Qatar, student's nationality was deemed as an important predictor of higher education choices. Accordingly, it was dichotomized into two subpopulations: non-Qatari (0) and Qatari (1).

Parental highest level of education. This variable consisted of four categories: $1=$ Less than high school, $2=$ Completed grade 12 or higher, $3=$ Diploma/associate degree after high school, and $4=$ Completed university degree. Level of parental education was initially recorded separately for fathers and mothers, but was later merged into a single variable so that the highest level of education of either parent is recorded.

Father's occupation and mother's occupation. Father's occupation was recorded in an open-ended item, and accordingly recoded into following categories: $1=$ Currently not working/retired, $3=$ Armed forces/police, $4=$ Clerk, $5=$ Professional, $6=$ Legislator. Mother's occupation was similarly coded, with the exception of category 1 (coded as Housewife/currently not working/retired), and there was no category 3 (armed forces/police). Unlike education, it would have been difficult to recode occupation into a single variable, for two reasons: a) there was a sizeable number of fathers in the army/police, unlike the mothers, and b) overwhelming majority of mothers were reported to be housewives, hence merging the two into a single category would have been misleading.

\section{Results}

The study only focused on the responses of those students who reported they planned to apply to college/university upon graduation from high school. All statistical analyses were carried out in Stata 14 using weighted data.

\subsection{Factor Analysis}

Exploratory factor analysis (EFA) was used to narrow down the list of 18 items to a smaller number of variables. This was done to simplify the interpretation and identify variables in order to create factor scores to be used later in regression analyses. The factorability of the 18 items was examined, and several well-recognized criteria for the factorability of a correlation were used. It was then observed that all items correlated at least .3 with at least one other item, suggesting reasonable factorability. The Kaiser-Meyer-Olkin (KMO) measure of sampling adequacy was .77, above the commonly recommended value of .65, and Bartlett's test of sphericity was significant $\left(\chi^{2}(153)=4070.611\right.$, $\mathrm{p}<.001$ ). Hence, factorability was assumed and it was deemed appropriate to proceed with factor analysis (Field, 2009).

Since the model consisted of variables on an ordinal (Likert) scale, the standard methods of performing factor analysis, which assume that variables are continuous, were not appropriate. Instead, factor analysis was performed using a polychoric correlation matrix, with an orthogonal rotation of the factors, thereby assuming that factors are not correlated with each other. Factor analysis revealed three factors with eigenvalues above 1.0 (Costello \& Osborne, 2005), explaining $79 \%$ of total variance, which was confirmed using a scree test.

After culling three items with low item-total correlations, 15 items were retained, with communalities .3 or higher, confirming that each item shared sufficient common variance with other items within each factor. Given these overall indicators, three factors were retained, with eight items assessing quality of education (.65), five cultural values (.71) and two items assessing the cost of education (.61).

Composite scores were created for each of the three factors, based on the mean of the items that had their primary loadings on each factor. Higher scores indicated greater importance of each of the factors in choosing a college/university. Scores for the three factors were subsequently used in multiple logistic regression analysis.

\subsection{Regression}

Ordinal logistic regression was performed to estimate the relationship between each of the three factors in choosing a college/university and students' gender, nationality, parental education father's and mother's occupation. It allowed us to estimate the association between each predictor (independent) and the outcome (dependent) variable, controlling for all other predictors.

\subsubsection{Factor 1: Quality of Education}

Two variables predicted the quality of education as an important factor in choosing a HEI: gender and parents' highest education level. Namely, respondents having at least one parent with a university degree had significantly higher odds to agree that the quality of education is an important factor $(\mathrm{OR}=2.06,95 \% \mathrm{CI}: 1.32,3.23)$, versus those 
whose parents had lower than high school degree. Likewise, male respondents had significantly lower odds of reporting the quality of education as an important factor ( $\mathrm{OR}=.77,95 \% \mathrm{CI}$ : $0.61,0.96)$, compared to females (Table $1)$.

Table 1. Ordinal logistic regression for Factor 1 (Quality of education) $(\mathrm{N}=1,021)$

\begin{tabular}{|c|c|c|c|}
\hline Variables & $O R(S E)$ & $95 \% C I$ & Prob. \\
\hline \multicolumn{4}{|l|}{ Gender } \\
\hline Male & $0.77(0.9)$ & $0.61-0.96$ & 0.02 \\
\hline \multicolumn{4}{|l|}{ Nationality } \\
\hline Qatari & $0.90(0.12)$ & $0.68-1.18$ & 0.44 \\
\hline \multicolumn{4}{|l|}{ Parents' highest education (lower than HS ref.) } \\
\hline Completed 12 grades or higher & $1.44(0.36)$ & $0.88-2.34$ & 0.15 \\
\hline Diploma/associate degree after $H S$ & $1.29(0.32)$ & $0.79-2.11$ & 0.31 \\
\hline Completed university degree & $2.06(0.47)$ & $1.32-3.23$ & 0.002 \\
\hline \multicolumn{4}{|l|}{ Father's occupation (senior officer, manager ref.) } \\
\hline Currently not working/retired & $1.35(0.35)$ & $0.82-2.23$ & 0.24 \\
\hline Armed forces/police & $0.95(0.24)$ & $0.58-1.54$ & 0.83 \\
\hline Clerk (secretary, cashier, office assistant) & $1.12(0.22)$ & $0.76-1.65$ & 0.58 \\
\hline Professional (engineer, doctor, lawyer...) & $1.05(0.15)$ & $0.79-1.40$ & 0.73 \\
\hline \multicolumn{4}{|l|}{ Mother's occupation (senior officer, manager ref.) } \\
\hline Housewife/currently not working/retired & $1.38(0.35)$ & $0.83-2.28$ & 0.21 \\
\hline Clerk (secretary, cashier, office assistant) & $1.27(0.40)$ & $0.68-2.37$ & 0.45 \\
\hline Professional (engineer, doctor, lawyer...) & $1.39(0.38)$ & $0.82-2.36$ & 0.23 \\
\hline
\end{tabular}

6.2.2 Factor 2: Cultural Values

Different demographic determinants were associated with considering cultural values as important in the choice of a HEI. Qatari respondents had significantly higher odds of reporting it as an important factor (OR: 3.47, 95\% CI: 2.63, 4.59), as well as respondents whose fathers were in the armed forces or police (OR: 2.33, 95\% CI: 1.48, 3.69) versus those whose fathers were in managerial and legislative occupations. Likewise, respondents whose mothers were housewives or unemployed had higher odds of reporting cultural values as important (OR: 1.75, 95\% CI: 1.06, 2.89). Male respondents had marginally lower odds (OR: .81, 95\% CI: $0.65,1.01)$, as well as respondents with a least one parent holding a post-high school diploma degree (OR: .37, 95\% CI: $0.23,0.58$ ), or a completed university degree (OR: $0.42,95 \%$ CI: $0.27,0.64$ ), compared to those whose parents had lower than high school education (Table 2). 
Table 2. Ordinal logistic regression for Factor 2 (Cultural values) $(\mathrm{N}=1,025)$

\begin{tabular}{|c|c|c|c|}
\hline Variables & $O R(S E)$ & $95 \% C I$ & Prob. \\
\hline \multicolumn{4}{|l|}{ Gender } \\
\hline Male & $0.81(0.9)$ & $0.65-1.01$ & 0.05 \\
\hline \multicolumn{4}{|l|}{ Nationality } \\
\hline Qatari & $3.47(0.49)$ & $2.63-4.59$ & 0.000 \\
\hline \multicolumn{4}{|l|}{ Parents' highest education (lower than HS ref.) } \\
\hline Completed 12 grades or higher & $0.81(0.19)$ & $0.51-1.29$ & 0.38 \\
\hline Diploma/associate degree after $H S$ & $0.37(0.09)$ & $0.23-0.58$ & 0.000 \\
\hline Completed university degree & $0.42(0.09)$ & $0.27-0.64$ & 0.000 \\
\hline \multicolumn{4}{|l|}{ Father's occupation (senior officer, manager ref.) } \\
\hline Currently not working/retired & $1.48(0.35)$ & $0.93-2.34$ & 0.09 \\
\hline Armed forces/police & $2.33(0.55)$ & $1.48-3.69$ & 0.000 \\
\hline Clerk (secretary, cashier, office assistant) & $1.14(0.23)$ & $0.77-1.67$ & 0.51 \\
\hline Professional (engineer, doctor, lawyer...) & $1.03(0.15)$ & $0.77-1.37$ & 0.86 \\
\hline \multicolumn{4}{|l|}{ Mother's occupation (senior officer, manager ref.) } \\
\hline Housewife/currently not working/retired & $1.75(0.45)$ & $1.06-2.89$ & $\mathbf{0 . 0 3}$ \\
\hline Clerk (secretary, cashier, office assistant) & $1.69(0.53)$ & $0.91-3.13$ & 0.09 \\
\hline Professional (engineer, doctor, lawyer...) & $1.60(0.43)$ & $0.94-2.71$ & 0.08 \\
\hline
\end{tabular}

\subsubsection{Factor 3: Cost of Education}

Male respondents had higher odds in agreeing that cost of education is an important factor (OR: 1.85, 95\% CI: 1.47, 2.31), as well as those whose fathers were in the armed forces or police (OR: 2.21, 95\% CI: 1.37, 3.57), and those in professional occupations (OR: 1.39, 95\% CI: 1.04, 1.85).

On the other hand, Qatari respondents had lower odds of agreeing that cost of education is an important factor (OR: 0.34, 95\% CI: $0.25,0.45)$. Respondents with at least one parent having a post-high school diploma or associate degree (OR: $0.59,95 \%$ CI: $0.37,0.96)$ and those with a completed university degree (OR: $0.49,95 \%$ CI: $0.32,0.75$ ) also had lower odds of considering cost of education as an important factor (Table 3 ). 
Table 3. Ordinal logistic regression for Factor 3 (Cost of education) $(\mathrm{N}=1,049)$

\begin{tabular}{|c|c|c|c|}
\hline Variables & $O R(S E)$ & $95 \% C I$ & Prob. \\
\hline \multicolumn{4}{|l|}{ Gender } \\
\hline Male & $1.85(0.21)$ & $1.47-2.31$ & 0.000 \\
\hline \multicolumn{4}{|l|}{ Nationality } \\
\hline Qatari & $0.34(0.05)$ & $0.25-0.45$ & 0.000 \\
\hline \multicolumn{4}{|l|}{ Parents' highest education (lower than HS ref.) } \\
\hline Completed 12 grades or higher & $0.76(0.18)$ & $0.47-1.22$ & 0.26 \\
\hline Diploma/associate degree after $H S$ & $0.59(0.14)$ & $0.37-0.96$ & $\mathbf{0 . 0 3}$ \\
\hline Completed university degree & $0.49(0.11)$ & $0.32-0.75$ & 0.001 \\
\hline \multicolumn{4}{|l|}{ Father's occupation (senior officer, manager ref.) } \\
\hline Currently not working/retired & $1.29(0.33)$ & $0.79-2.14$ & 0.30 \\
\hline Armed forces/police & $2.21(0.54)$ & $1.37-3.57$ & 0.001 \\
\hline Clerk (secretary, cashier, office assistant) & $1.37(0.27)$ & $0.93-2.00$ & 0.11 \\
\hline Professional (engineer, doctor, lawyer...) & $1.39(0.20)$ & $1.04-1.85$ & $\mathbf{0 . 0 3}$ \\
\hline \multicolumn{4}{|l|}{ Mother's occupation (senior officer, manager ref.) } \\
\hline Housewife/currently not working/retired & $0.81(0.21)$ & $0.48-1.36$ & 0.43 \\
\hline Clerk (secretary, cashier, office assistant) & $0.82(0.27)$ & $0.43-1.57$ & 0.56 \\
\hline Professional (engineer, doctor, lawyer...) & $1.07(0.29)$ & $0.62-1.83$ & 0.82 \\
\hline
\end{tabular}

\section{Discussion}

Data analysis revealed a range of influences that shape the post-secondary educational paths young adolescents aspire to in Qatar. Three main aspects of HEI experience were identified as predictors of student choices: quality of education, cultural values, and cost of education. The results further demonstrate that these three influences intersect, to varying degrees, with a range of individual attributes, including gender and nationality. Student household characteristics, specifically parent education and parent occupation, were also found to be important predictors of the choices students make.

\subsection{Quality of Education}

Past studies investigating the college/university selection process generally show that gender is a significant source of influence in the choice decisions of students, and gender gaps have been found to affect male and female student choice and aspiration for college/university enrollment (Ceja, 2001; Cho et al., 2008; Perez \& McDonough, 2008). The study findings support those studies, and indicate a significant and positive correlation between student gender and determinants of college/university choice. More specifically, student gender appears to be strongly associated with perceptions of quality in higher education, mirroring recent research by Akareem and Hossain (2016). As was expected, female students tend to report the quality of education as a determinant of choice more than males do.

Another important variable that is associated with perceptions of education quality, and that remains a salient college/university choice determinant, is parental education. The study results indicate that students with highly educated parents were significantly more likely to value quality of education. These results echo the findings noted in past research on the influence parents wield on their children's education. For example, Cabrera and La Nasa (2001), Ceja (2006), and Hamrick and Stage (2004) contend that parental education is a key predictor of students' future educational paths. Other documented research confirms that the role of parents - viewed along with other family members and teachers as significant others - is of central importance to the choices students make (Bers \& Galowich, 2002; Ceja, 2004; Hossler, Schmit, \& Vesper, 1999). Overall, of the different parental variables discussed in past research, parents' level of education is generally acknowledged as having the greatest potential to impact student choice of a college/university (Chenoweth \& Galliher, 2004; Dubow, Boxer \& Huesmann, 2009). 


\subsection{Cultural Values}

The study findings are in line with previous research that confirms the impact of cultural beliefs on high school students' choice decisions for enrollment in a college/university. Social and cultural influences have been identified in the literature as important predictors of student enrollment choices and comprise institution and student related factors, along with the larger social environment, including the family, peers and other important reference groups (Lovenheim \& Reynolds, 2012; Veloutsou, Lewis \& Paton, 2004).

The study results further indicate a gender gap that shapes students' views of the role of culture as a predictor of their HEI choice decisions, with females significantly more likely to report cultural values as a main driver that influences their decisions. Research carried out by Van der Vleuten et al. (2016) highlights the role of cultural beliefs, referring to persistent gender gaps in students' educational choices, which are associated with gender-based stereotypes: for example, males tend to opt for science-oriented subjects while females tend to choose non-science subjects. Other work done by Moogan and Baron (2003) similarly showed that females tend to be more anxious about moving away from home as compared to males.

Student's nationality emerged as an important driver of the choices they make regarding their post-secondary education plans. Qatari students reported culture as a predictor of their enrollment choices more frequently than their non-Qatari counterparts did, and were more likely to find cultural norms to be a significant determinant of higher education enrollment choices. These findings need to be interpreted against the backdrop of the local culture in Qatar.

It may be argued that Qatari students tend to prefer attending Qatar's public national institution of higher education, Qatar University, as it best reflects their cultural norms. Qatar University adopts a gender-segregated policy across all of its colleges. Gender is an important determinant of school choice in Qatar, as is evident from the existence of single sex schooling at all levels of public education. The study's results may also be understood in light of the key role that the Arabic language and (Islamic) religion play. In particular, in Qatar and the broader Arabian Gulf region (GCC), Arabic and Islamic studies (Sharia'h) are indisputably regarded as important and necessary at different levels of education (Karmani, 2011; Rostron, 2009).

Whether student responses imply that the subjects of Arabic and Islamic studies are key drivers when Qatari students and their families choose a college/university for their children remains to be seen. It would also be interesting to see whether and how the perceived threat of English language teaching to Arabic and/or Islam that Hudson (2013) and Solloway (2016) refer to actually influences decisions regarding student educational paths. For Charise (2007), the teaching of English in the GCC countries is "an ideological burden which cannot be dismissed as benign nor regarded as any less palpable than the explicit religiosity of Arabic in the Islamic context" (p. 10).

Equally important are parental characteristics that bear upon students' reports regarding their college/university choices, namely parental education and occupation. Firstly, students with parents holding a lower than high school degree appeared to be significantly more like to report cultural values as an important driver of their choice decision, compared to those whose parents attained higher education. A substantial body of research provides evidence of the relationship between parents' education level and their children's educational aspiration. Rockwell (2011) and Smoke (2013), for instance, concluded that children's decisions to attend college are primarily influenced by their parents' education level and children of highly educated parents are often under pressure to attend college to meet their parents' expectations.

Secondly, the results suggest that students whose fathers were in the armed forces or police were significantly more likely to report the importance of cultural values in the choices they make, compared to those whose fathers engage in managerial or legislative professions. Students whose mothers were housewives or unemployed tend to also consider cultural values as important drivers of their educational choices, compared to those whose mothers were in managerial or legislative occupations. Previous research by McDonough (1997) reveals the support parents provide is a form of cultural capital.

\subsection{Cost of Education}

The results attained from this study also reveal the cost of education as a major factor in students' choice decisions. Alongside a HEI's academic reputation, the cost of tuition and career prospects are the top deciding factors for where students choose to attend college or university (Holdsworth \& Nind, 2006; Maringe, 2006). Research bears evidence of the strong influence of the perceived cost of tuition on students' HEI choice and enrollment decisions: students often weigh the choices they make against tuition charges (Goldrick-Rab \& Pfeffer, 2009; Hoxby \& Turner, 2013). 
The study found that the relationship between gender and the cost of education as a determinant of their choice decisions was only applicable in the case of male students. The data revealed that male students were significantly more likely to agree that tuition fees are an important determinant of the choice they make, as compared to their female counterparts. This contrasts the results from past research, which indicate that the cost of attendance is the main reason students - regardless of their gender - forgo first-choice colleges and universities. However, it is important to analyze this finding in light of the local context and societal norms. Male students are more likely to be expected to find meaningful employment at a young age, and to support their families. Since the responsibility of being the main breadwinner is generally not placed on females, their education is more likely to be supported by the family, which could be one of the reasons why cost is not mentioned as frequently as a concern.

Nationality emerged as another important factor that influences students' views of the cost of education. Namely, non-Qatari students were significantly more likely to report the cost of tuition as a key determinant in their choice of college/university. These results may be interpreted in light of the education market, as well as the differences in entitlements and benefits that Qatari and non-Qatari employees in the country enjoy.

Qatar is home to the most expensive private non-profit universities in the Arab region, with an average annual tuition cost of $\$ 50,000$ per year compared to $\$ 31,231$ in the United States (Wheeler, 2015). Therefore, higher education in Qatar entails real financial burdens for many residents who often resort to bank loans to cover their children's educational expenses and struggle paying them back; other students leave the country to seek degrees overseas (Kamel \& Qazi, 2015). While Qatari nationals can attend the nation's only public university (Qatar University) at no cost, as well as obtained fully funded scholarships for studies abroad, long-term residents living in the country have to either pay if admitted to the public university, or pay the much steeper fees to attend one of the private universities in the Education City. Alternatively, many parents opt to send their children back to their country of origin to complete higher education, where the tuition fees are more affordable.

Considering the impact of parental variables on respondents' views of the cost of education as a predictor of college/university choice decisions, this study's data yielded mixed results. It is clear that respondents with at least one parent holding a post-high school or higher degree were less likely to report the cost of education as an important factor that shapes college/university attendance choices, compared to respondents with parents having only high school or lower level education. This could imply that parents who are more highly educated emphasize the importance of their children's education, and are therefore willing to invest more in it.

Respondents whose fathers work in the armed forces or the police were highly likely to report the cost of education as an important choice predictor, more than those whose fathers engage in managerial or legislative professions. Here the peculiar socio-economic context of Qatar and the broader Middle East region must be noted, where those working in the security forces tend to be lower educated and earn lower incomes. Particularly in Qatar, due to the small citizen population, the majority of lower and mid-level positions in the army and police are staffed with residents coming from less developed countries of the region (such as Yemen, Sudan, Pakistan, and Iran). In that light, it becomes evident why cost of education would surface as an important factor for the respondents when making their choice for college/university. Another possible explanation that can account for observations above may be attributed to inadequate knowledge, or even lack of awareness, regarding college prices across national and socio-economic status groups, leading to erroneous reports of the importance of cost as a factor in choosing a higher education institution. These results corroborate similar findings reported in other studies prior work by (McDonough \& Calderone, 2006).

\section{Conclusion and Recommendations}

The purpose of this study was twofold: i) to investigate the factors that drive high school students' HEI choices in Qatar, and ii) to analyze whether and to what extent different demographic characteristics can predict the importance of those factors. Results provided evidence that quality of education, cultural values, and cost of education are important determinants and were predicted, to varying degrees, by student's gender, nationality, parental education and occupation. Findings of the study provide valuable insights for policymakers and educators in Qatar. The results call attention to the need for supporting student choices, therefore school counseling can play a key role in providing guidance for students, beginning at the preparatory school level. As growing numbers of Qatar's pre-college youth plan to enter tertiary education, it is incumbent that schools engage in preparing students for their post-secondary educational plans. Understanding the varying levels of importance that different student demographic subgroups place on certain enrollment factors is key to tailoring the approach. Student counselors can play an important role in assisting students to make the right choice decisions regarding their future enrollment in HEIs, as counseling can provide insights into the barriers, perceived or real, that may impede students' choice decisions. The onus also rests 
with families, and student counseling would need to combine parental involvement in children's plans regarding how and when to make their choices towards post-secondary pathways. This is particularly important in cases where parents themselves have lower education levels and place inadequate emphasis on their children's further education. Where possible, availability of financial aid and scholarships should be made more visible, so that students who perceive cost as a hurdle are made aware of potential funding options. Overall, there should be greater and more transparent information on challenges and opportunities for college/university education, including presentations, tutorials, seminars, and school teaching staff-student meetings to enable students to choose courses, programs and HEIs offering what is most important and pertinent to them.

\subsection{Limitations}

Whilst this study used the questionnaire as a data collection technique, it could have been enhanced with additional information. Using a qualitative method would be useful to complement the survey data and hence provide a richer and more robust set of data. This would help to capture more meaningful perspectives of participants ,and enrich the quality and depth of the data. Another limitation of our study is its focus on a sample that is constrained by traits specific to the Arabian Gulf and that may not be representative of other populations with different socio-economic characteristics.

\subsection{Future Research}

There is need for future research to identify in-depth the developmental trends and determine variable patterns of young adolescents over the high school years. Moreover, since most studies solicit only student opinion, it is of particular importance to also attend to the potential influences of significant others and particularly examine parents' perspective in order to compare similarities and differences in judgements. This study would therefore benefit from also including parents and/or teachers to obtain an alternative perspective and provide a more comprehensive picture of what factors influence students' higher education enrollment decisions and the range of options available to them.

\section{Acknowledgments}

This work was supported by the Social and Economic Survey Research Institute, at Qatar University. The authors would like to thank all the students who took part in the 2015 Qatar University Image Study. The authors would also like to thank Dr. Abdoulaye Diop, Dr. Nizam Khan, Dr. Elmogeira Elawad, and Mr. Isam Mohamed Abdelhameed, Samah Ahmed in giving so generously of their time at various stages of the data collection and entry.

\section{References}

Absher, K. \& Crawford, G. (1996). Marketing the community college starts with understanding students' perspectives. Community College Review, 23(4), 59-67. https://doi.org/10.1177/009155219602300406

Agrey, L. \& Lampadan, N. (2014). Determinant factors contributing to student choice in selecting a university. Journal of Education and Human Development, 3(2), 391-404.

Baksh, A., \& Hoyt, J. E. (2001). The effect of academic scholarship on college attendance. College and University, 74(4), 3-8.

Bartlett, L., Fredrick, M., Gulbrandsen, T., \& Murillo, E. (2002). The marketisation of education: Public schools for private ends. Anthropology and Education Quarterly, 33(1), 1-25. https://doi.org/10.1525/aeq.2002.33.1.5

Belasco, A. S. (2013). Creating college opportunity: School counselors and their influence on postsecondary enrollment. Research in Higher Education, 54(7), 781-804. https://doi.org/10.1007/s11162-013-9297-4

Bers, T. H., \& Galowich, P. M. (2002). Using survey and focus group research to learn about parents' roles in the community college choice process. Community College Review, 29(4), 67-82. https://doi.org/10.1177/009155210202900404

Bok, D. (2003). Universities in the marketplace: The commercialisation of higher education. Princeton, New Jersey: Princeton University Press.

Brewer, D. J., Augustine, C. H., Zellman, G. L., Ryan, G. W., Goldman, C. A., \& Ryan, G. (2007). Education for a New Era: Design and implementation of $\mathrm{K}-12$ education reform in Qatar. Santa Monica, CA: RAND Corporation. Retrieved from: http://www.rand.org/pubs/monographs/MG548.html

Briggs, S. (2006). An exploratory study of the factors influencing undergraduate student choice: The case of higher education in Scotland. Studies in Higher Education, 31(6), 705-722. https://doi.org/10.1080/03075070601004333 
Brennan, L. (2001). How prospective students choose universities: A buyer behaviour perspective (Unpublished doctoral dissertation). The University of Melbourne, Australia.

Cabrera, A. F., \& La Nasa, S. M. (2000). Understanding the college-choice process. New Directions for Institutional Research, 2000(107), 5-22. https://doi.org/10.1002/ir.10701

Cabrera, A. F., \& La Nasa, S. M. (2001). On the path to college: Three critical tasks facing America's disadvantaged. Research in Higher Education, 42(2), 119-149. https://doi.org/10.1023/A:1026520002362

Ceja, M. A. (2001). Applying, choosing, and enrolling in higher education: Understanding the college choice process of first-generation Chicana students (Unpublished doctoral dissertation). The University of California, Los Angeles, USA.

Ceja, M. (2004). Chicana college aspirations and the role of parents. Journal of Hispanic Higher Education, 3(4), 1-25. https://doi.org/10.1177/1538192704268428

Ceja, M. (2006). Understanding the role of parents and siblings as information sources in the college choice process of Chicana students. Journal of College Student Development, 47(1), 87-104. https://doi.org/10.1353/csd.2006.0003

Charise, A. (2007). More English, less Islam? An overview of English language functions in the Arabian/Persian Gulf. University of Toronto Website, from http://homes.chass.utoronto.ca/ cpercy/courses/eng6365-charise.htm

Chatfield, H. K., Lee, S. J., \& Chatfield, R. E. (2012). The analysis of factors affecting choice of college: A case study of University of Nevada Las Vegas Hotel college students. Journal of Hospitality \& Tourism Education, 24(1), 26-33. https://doi.org/10.1080/10963758.2012.10696659

Chenoweth, E., \& Galliher, R. V. (2004). Factors influencing college aspirations of rural West Virginia high school students. Journal of Research in Rural Education, 19(2), 1-14. Retrieved from http://www.jrre.psu.edu/articles/19-2.pdf Google Scholar

Cho, S. J., Hudley, C., Lee, S., Barry, L., \& Kelly, M. (2008). Roles of gender, race, and SES in the college choice process among first-generation and nonfirst-generation students. Journal of Diversity in Higher Education, 1(2), 95-107. https://doi.org/10.1037/1938-8926.1.2.95

Cohen, P. (2016, May 10). It's a tough job market for the young without college degrees. The New York Times. Retrieved

from https://www.nytimes.com/2016/05/11/business/economy/its-a-tough-job-market-for-the-young-without-collegedegrees.html

Chung, K. C., Fam, K. S., \& Holdsworth, D. K. (2009). Impact of cultural values on young consumers' choice of international tertiary education. Asia-Pacific Journal of Business Administration, 1(1), 54-67. https://doi.org/10.1108/17574320910942178

Costello, A. B., \& Osborne, J. W. (2005). Best practices in exploratory factor analysis: Four recommendations for getting the most from your analysis. Practical Assessment, Research, \& Evaluation, 10, 1-9.

Crist, J. T., \& Powell, J. J. (2017). Higher education systems and institutions, Qatar. In J.C. Shin, P. Teixeira (Eds.), Encyclopedia of International Higher Education Systems and Institutions (pp. 1-5). Dordrecht, The Netherlands: Springer Science \& Business Media. https://doi.org/10.1007/978-94-017-9553-1_484-1

Davignon, P. (2016). Factors influencing college choice and satisfaction among students at Christian colleges and universities. Religion \& Education, 43(1), 77-94. https://doi.org/10.1080/15507394.2015.1090811

Drewes, T., \& Michael, C. (2006). How do students choose a university? An analysis of applications to universities in Ontario, Canada. Research in Higher Education, 47(7), 781-800. https://doi.org/10.1007/s11162-006-9015-6

Dubow, E. F., Boxer, P., \& Huesmann, L. R. (2009). Long-term effects of parents' education on children's educational and occupational success: Mediation by family interactions, child aggression, and teenage aspirations. Merrill-Palmer Quarterly (Wayne State University. Press), 55(3), 224-249. https://doi.org/10.1353/mpq.0.0030

Dunnett, A., Moorhouse, J., Walsh, C., \& Barry, C. (2012). Choosing a university: A conjoint analysis of the impact of higher fees on students applying for university in 2012. Tertiary Education and Management, 18(3), 199-220. https://doi.org/10.1080/13583883.2012.657228 
Fernandez, J. L. (2010). An exploratory study of factors influencing the decision of students to study at Universiti Sains Malaysia. Kajian Malaysia: Journal of Malaysian Studies, 28(2), 107-136.

Field, A. (2009). Discovering Statistics using SPSS. London: Sage.

Git, A. (2014, March 20). High school diploma not enough? More companies want college grads. MoneyWatch. Retrieved from https://www.cbsnews.com/news/high-school-diploma-not-enough-more-companies-want-college-grads/

Goldrick-Rab, S., \& Pfeffer, F. T. (2009). Beyond access: Explaining socioeconomic differences in college transfer. Sociology of Education, 82(2), 101-125. https://doi.org/10.1177/003804070908200201

Hamrick, F. A., \& Stage, F. K. (2004). College predisposition at high-minority enrollment, low-income schools. Review of Higher Education, 27(2), 151-168. https://doi.org/10.1353/rhe.2003.0058

Hemsley-Brown, J. (1999). College choice: Perceptions and priorities. Educational Management \& Administration, 27(1), 85-98. https://doi.org/10.1177/0263211X990271007

Holbrook, M. (2005). Marketing education as bad medicine for society: The gorilla dances. Journal of Public Policy and Marketing, 24(1), 134-145. https://doi.org/10.1509/jppm.24.1.143.63906

Holdsworth, D. K., \& Nind, D. (2006). Choice modeling New Zealand high school seniors' preferences for university education. Journal of Marketing for Higher Education, 15(2), 81-102. https://doi.org/10.1300/J050v15n02_04

Hossler, D., Braxton, J., \& Coopersmith, G. (1989). Understanding student college choice. In J. C. Smart (Ed.), Higher education: Handbook of theory and research (pp. 231-288). New York: Agathon Press.

Hossler, D., Schmit, J., \& Vesper, N. (1999). Going to college: How social, economic, and educational factors influence the decisions students make. Baltimore, Maryland: Johns Hopkins University Press.

Hoxby, C., \& Turner, S. (2013). Expanding college opportunities for high-achieving, low income students. Education Next, 13(4). Retrieved from https://search.proquest.com/docview/1437312606?pq-origsite=gscholar

Hudson, P. (2013). Tiptoeing through the minefield: Teaching English in higher educational institutes in the United Arab Emirates (Unpublished doctoral dissertation). Canterbury Christ Church University, U.K.

Johnston, T. C. (2010). Who and what influences choice of university? Student and university perceptions. American Journal of Business Education, 3(10), 15-24. https://doi.org/10.19030/ajbe.v3i10.484

Joseph, M. \& Joseph B. (2000). Indonesian students' perceptions of choice criteria in the selection of a tertiary institution: Strategic implications. International Journal of Educational Management, 14(1), 40-44. https://doi.org/10.1108/09513540010310396

Kamel, E., \& Qazi, S. (2015, 08 March). Qatar's universities are too expensive for many expats. Al-Fanar Media Retrieved from https://www.al-fanarmedia.org/2015/03/qatars-universities-expensive-many-expats/

Karmani, S. (2011). On perceptions of the socialising effect of English medium Education on students at a Gulf Arab university with particular reference to the United Arab Emirates (Unpublished doctoral dissertation). University of Exeter.

Kim, D. (2004). The effect of financial aid on students' college choice: Differences by racial groups. Research in Higher Education, 45(1), 43-70. https://doi.org/10.1023/B:RIHE.0000010046.57597.43

Kim, D. H., \& Schneider, B. (2005). Social capital in action: Alignment of parental support in adolescents' transition to postsecondary education. Social Forces, 84(2), 1181-1206. https://doi.org/10.1353/sof.2006.0012

Kinzie, J., Palmer, M., Hayek, J., Hossler, D., Jacob, S. A., \& Cummings, H. (2004). Fifty years of college choice: Social, political and institutional influences on the decision-making process. New Agenda Series (Volume 5, Number 3). Lumina Foundation for Education. Indianapolis, IN: Lumina Foundation for Education. Retrieved from https://www.luminafoundation.org/files/publications/Hossler.pdf

Krezel, J., \& Krezel, Z. A. (2017). Social influence and student choice of higher education institution. Journal of Education Culture and Society, 7(2), 116-130. https://doi.org/10.15503/jecs20172.116.130

Lagrosen, S., Seyyed-Hashemi, R., \& Leitner, M. (2004). Examination of the dimensions of quality in higher education. Quality assurance in education, 12(2), 61-69. https://doi.org/10.1108/09684880410536431

Lang, W. D. (2009). Articulation, transfer, and student choice in a binary post-secondary system. Higher Education, 57(3), 355-371. https://doi.org/10.1007/s10734-008-9151-3 
Lovenheim, M. F., \& Reynolds, C. L. (2013). The effect of housing wealth on college choice: Evidence from the housing boom. Journal of Human Resources, 48(1), 1-35. https://doi.org/10.1353/jhr.2013.0001

Maringe, F. (2006). University and course choice: Implications for positioning, recruitment and marketing. International Journal of Educational Management, 20(6), 466-479. https://doi.org/10.1108/09513540610683711

Mazzarol, T. W., Choo, S., and Nair, V. S. (2001). Australia and the Indian postgraduate science \& technology market: Examining why Indian students choose to study in countries other than Australia. Canberra, Australia: Australian Education International Department of Education, Training and Youth Affairs (DETYA).

McDonough, P. M. (1997). Choosing colleges: How social class and schools structure opportunity. Albany: State University of New York Press.

Ministry of Development Planning and Statistics (2017). Sukkan or better life. Population Newsletter, 35. Retrieved from https://www.mdps.gov.qa/en/statistics1/pages/default.aspx.

Ministry of Development Planning and Statistics (2018). Population archive. Retrieved from https://www.mdps.gov.qa/en/statistics1/StatisticsSite/pages/population.aspx

Moogan, Y., \& Baron, S. (2003). An analysis of student characteristics within the student decision making process. Journal of further and Higher Education, 27(3), 271-287. https://doi.org/10.1080/0309877032000098699

Newman, F., Couturier, L., \& Scurry, J. (2004). The future of higher education: Rhetoric, reality, and the risk of the market. San Francisco: Jossey-Bass.

Noel-Levitz (2012). Why did they enroll? The factors influencing college choice. National Research Report. Coralville, Iowa: Author. Retrieved from https://www.ruffalonl.com/documents/shared/Papers_and_Research/2012/2012_Factors_to_Enroll.pdf

Nora, A. (2004). The role of habitus and cultural capital in choosing a college, transitioning from high school to higher education, and persisting in college among minority and nonminority students. Journal of Hispanic Higher Education, 3(2), 180-208. https://doi.org/10.1177/1538192704263189

Paulsen, M. B., \& John, E. P. S. (2002). Social class and college costs: Examining the financial nexus between college choice and persistence. The Journal of Higher Education, 73(2), 189-236. https://doi.org/10.1080/00221546.2002.11777141

Perez, P. A., \& McDonough, P. M. (2008). Understanding Latina and Latino college choice: A social capital and chain migration analysis. Journal of Hispanic Higher Education, 7(3), 249-265. https://doi.org/10.1177/1538192708317620

Perna, L. W. (2006). Studying college access and choice: A proposed conceptual model. In J. C. Smart (Ed.), Higher education: Handbook of theory and research, 21 (pp. 99-157). New York: Springer.

Perna, L. W., \& Steele, P. E. (2011). The role of context in understanding the contributions of financial aid to college opportunity. Teachers College Record, 113(5), 895-933.

Plank, S. B., \& Jordan, W. J. (2001). Effects of information, guidance, and actions on postsecondary destinations: A study of talent loss. American Educational Research Journal, 38(4), 947-979. https://doi.org/10.3102/00028312038004947

Price, I. F., Matzdorf, F., Smith, L., \& Agahi, H. (2003). The impact of facilities on student choice of university. Facilities, 21(10), 212-222. https://doi.org/10.1108/02632770310493580

Rockwell, C. (2011). Factors affecting parental involvement with children's education: a qualitative study of parent's socioeconomic status, level of education, and parent-school relationship. Perspectives (University of New Hampshire), 94-98.

Rostron, M. (2009). Liberal arts education in Qatar: Intercultural perspectives. Intercultural Education, 20(3), 219-229. https://doi.org/10.1080/14675980903138517

Sharrock, G. (2000). Why students are not 'just' customers. Journal of Higher Education Policy and Management, 22(2), 149-164. https://doi.org/10.1080/713678141

Smoke, K. (2013). The effect of parent's education on the educational aspirations of college students. Academic Forum, 31, 2013-14. 
Solloway, A. J. (2016). English-medium instruction in higher education in the United Arab Emirates: The perspectives of students (Unpublished doctoral dissertation). The University of Exeter, U.K.

Somers, P., Haines, K., \& Keene, B. (2006). Toward a theory of choice for community college students. College Journal of Research and Practice, 30(1), 53-67. https://doi.org/10.1080/10668920500248886

Van der Klaauw, W. (2002). Estimating the effect of financial aid offers on college enrollment: A regression-discontinuity approach. International Economic $\quad$ Review, 43(4), 1249-1287. https://doi.org/10.1111/1468-2354.t01-1-00055

Veloutsou, C., Lewis, J. W., \& Paton, R. A. (2004). University selection: Information requirements and importance. International Journal of Educational Management, 18(3), 160-171. https://doi.org/10.1108/09513540410527158

Wheeler, D. (2015, January 28). Qatar's private universities are the most expensive in the region. Al-Fanar Media. Retrieved from https://www.al-fanarmedia.org/2015/01/qatar-higher-education-costs-highest-region/

Wiese, M. D. (1994). College choice cognitive dissonance: Managing student/institution fit. Journal of Marketing for Higher Education, 5(1), 35-47. https://doi.org/10.1300/J050v05n01_04

Wiese, M., Van Heerden, C. H., \& Jordaan, Y. (2010). The role of demographics in students' selection of higher education institutions. Acta Commercii, 10(1), 150-163. https://doi.org/10.4102/ac.v10i1.124

Yusof, M., Ahmad, S. N. B., Tajudin, M., \& Ravindran, R. (2008). A study of factors influencing the selection of a higher education institution. UNITAR e-journal, 4(2), 27-40. 